\title{
Proposal of the genera Anaerococcus gen. nov., Peptoniphilus gen. nov. and Gallicola gen. nov. for members of the genus Peptostreptococcus
}

Department of

Microbiology, Gifu

University, School of

Medicine Tsukasa-machi 40,

Gifu 500, Japan

\author{
Takayuki Ezaki, Yoshiaki Kawamura, Na Li, Zhi-Yu Li, Licheng Zhao \\ and Shin-ei Shu
} Author for correspondence: Takayuki Ezaki. Tel: +81 58267 0155. Fax: +81 582670156.
e-mail: tezaki@cc.gifu-u.ac.jp
Members of genus Peptostreptococcus have previously been found to be distantly related to the type species, Peptostreptococcus anaerobius, on the basis of 165 rDNA sequence similarities. They were divided into three major phylogenetic groups, and their peptidoglycan structure and biochemical traits differed between groups. The reclassification of the species of these three groups into three new genera, Peptoniphilus gen. nov., Anaerococcus gen. nov. and Gallicola gen. nov., is proposed. The genus Peptoniphilus gen. nov. includes the following butyrate-producing, non-saccharolytic species that use peptone and amino acids as major energy sources: Peptoniphilus asaccharolyticus comb. nov. (type species), Peptoniphilus lacrimaris comb. nov., Peptoniphilus harei comb. nov., Peptoniphilus indolicus comb. nov. and Peptoniphilus ivorii comb. nov. The genus Anaerococcus gen. nov. contains the saccharolytic, butyrate-producing species Anaerococcus prevotii comb. nov. (type species), Anaerococcus tetradius comb. nov., Anaerococcus lactolyticus comb. nov., Anaerococcus hydrogenalis comb. nov., Anaerococcus vaginalis comb. nov. and Anaerococcus octavius sp. nov. The genus Gallicola gen. nov. contains a single species, Gallicola barnesae comb. nov.

Keywords: Peptostreptococcus, taxonomy, Anaerococcus, Peptoniphilus, Gallicola

\section{INTRODUCTION}

In a previous study, we determined the $16 \mathrm{~S}$ rDNA sequences of all members of the genus Peptostreptococcus and reported that the members of genus were divided into five phylogenetic groups (Li et al., 1994). This observation was later confirmed by Collins et al. (1994). These authors examined a large number of clostridial $16 \mathrm{~S}$ rRNA sequences and reported that the genus Clostridium contained phylogenetically distinct species. They proposed that these organisms be classified into 19 phylogenetic groups. The peptostreptococci were scattered over different groups of the clostridia. In particular, no other member of the genus Peptostreptococcus clustered together with the type species, Peptostreptococcus anaerobius. The phylogen-

Abbreviation: PYG, peptone/yeast extract/glucose.

The GenBank/EMBL/DDBJ accession numbers for the 16S rDNA sequences determined in this study are D14145, D14152, D14153 and AB038359AB038361. etic groups of peptostreptococci correlated well with groups based on peptidoglycan structure. Biochemical tests and peptidoglycan structure could differentiate each of the groups. The new genera Micromonas and Finegoldia were proposed for the species of one group (Murdoch \& Shah, 1999). In this study, we propose three new genera for the members of the remaining three groups.

\section{METHODS}

Bacterial strains and 16S rDNA sequences. The strains and $16 \mathrm{~S}$ rDNA accession numbers of the peptostreptococci and reference species used in this study are listed in Table 1.

Analysis of sequence data. About $1440 \mathrm{bp}$ spanning positions 50-1490 of $16 \mathrm{~S}$ rDNA sequences were used for multiple alignment. rDNA sequences were aligned by using CLUSTAL w (Thompson et al., 1994). Phylogenetic distances were calculated by the neighbour-joining method (Saitou \& Nei, 1986) with and without gaps. Bootstrap analysis was performed 1000 times and the results are indicated in Fig. 1. 
Table 1. Organisms used in this study

Accession numbers in bold indicate sequences determined in this study.

\begin{tabular}{|c|c|}
\hline Strain & 16S rDNA sequence accession no. \\
\hline Clostridium coccoides DSM 2088 & M59057 \\
\hline Clostridium difficile DSM 11209 & $\mathrm{X} 73450$ \\
\hline Clostridium ghonii DSM 10636 & $\mathrm{X} 73451$ \\
\hline Clostridium oroticum ATCC $13619^{\mathrm{T}}$ & M59109 \\
\hline Clostridium perfringens ATCC $13124^{\mathrm{T}}$ & M59103 \\
\hline Clostridium sordellii ATCC 9714 & M59105 \\
\hline Coprococcus catus VPI C6-61 ${ }^{\mathrm{T}}$ & AB038359 \\
\hline Coprococcus eutactus ATCC $27759^{\mathrm{T}}$ & D14148 \\
\hline Eubacterium cellulosolvens ATCC $43171^{\mathrm{NT}}$ & L34613 \\
\hline Finegoldia magna ATCC $15794^{\mathrm{T}}$ & D14149 \\
\hline Micromonas micros GIFU 7701 & D14143 \\
\hline Peptococcus niger ATCC $27731^{\mathrm{T}}$ & X55797 \\
\hline Peptostreptococcus anaerobius ATCC $27337^{\mathrm{T}}$ & L04168 \\
\hline Peptostreptococcus asaccharolyticus ATCC $14963^{\mathrm{T}}$ & D14138 \\
\hline Peptostreptococcus barnesae DSM $3244^{\mathrm{T}}$ & AB038361 \\
\hline Peptostreptococcus harei DSM $10020^{\mathrm{T}}$ & Y07839 \\
\hline Peptostreptococcus hydrogenalis GIFU $7662^{\mathrm{T}}$ & D14140 \\
\hline Peptostreptococcus indolicus ATCC $29427^{\mathrm{T}}$ & D14147 \\
\hline Peptostreptococcus ivorii DSM $10022^{\mathrm{T}}$ & Y07840 \\
\hline Peptostreptococcus lacrimalis GIFU 7667 & D14141 \\
\hline Peptostreptococcus lactolyticus GIFU $8586^{\mathrm{T}}$ & D14154 \\
\hline Peptostreptococcus octavius NCTC $9810^{\mathrm{T}}$ & Y07841 \\
\hline Peptostreptococcus prevotii ATCC $9321^{\mathrm{T}}$ & D14139 \\
\hline Peptostreptococcus tetradius GIFU $7672^{\mathrm{T}}$ & D14142 \\
\hline Peptostreptococcus vaginalis GIFU $12669^{\mathrm{T}}$ & D14146 \\
\hline Peptostreptococcus genospecies 1 GIFU 7717 & D14145 \\
\hline Peptostreptococcus genospecies 2 GIFU 7946 & D14152 \\
\hline Peptostreptococcus genospecies 3 GIFU 8124 & D14153 \\
\hline Peptostreptococcus genospecies 4 GIFU 7729 & AB038360 \\
\hline Ruminococcus albus ATCC $27210^{\mathrm{T}}$ & X85098 \\
\hline Ruminococcus bromii ATCC $27255^{\mathrm{T}}$ & X85099 \\
\hline Ruminococcus callidus VPI 57-31 ${ }^{\mathrm{T}}$ & $\mathrm{X} 85100$ \\
\hline Ruminococcus flavefaciens NCFB $2213^{\mathrm{T}}$ & $\mathrm{X} 83430$ \\
\hline Ruminococcus gnavus ATCC $29149^{\mathrm{T}}$ & D14136 \\
\hline Ruminococcus hansenii ATCC $27752^{\mathrm{T}}$ & D14155 \\
\hline Ruminococcus lactaris ATCC $29176^{\mathrm{T}}$ & L76602 \\
\hline Ruminococcus obeum ATCC $29174^{\mathrm{T}}$ & X85101 \\
\hline Ruminococcus productus ATCC $27340^{\mathrm{T}}$ & D14144 \\
\hline Ruminococcus torques ATCC $27756^{\mathrm{T}}$ & L76604 \\
\hline Sarcina maxima DSM $316^{\mathrm{T}}$ & X76650 \\
\hline Sarcina ventriculi GIFU $7886^{\mathrm{T}}$ & D14151 \\
\hline
\end{tabular}

Other methods. Peptidoglycan structure and biochemical traits were determined by methods described before (Li et al., 1992).

\section{RESULTS AND DISCUSSION}

Peptostreptococcus anaerobius, the type species of the genus Peptostreptococcus, clustered with Clostridium sordellii and Clostridium difficile in Fig. 1 in a phylogenetic analysis based on $16 \mathrm{~S}$ rDNA sequences. The other current members of the genus Peptostreptococcus were grouped in three different groups. These results were consistent when phylogenetic distances were calculated with and without gaps. Therefore, only the result with gaps is shown in Fig. 1. The species in group 1 were non-saccharolytic and had ornithine as the diamino acid in their peptidoglycan. Their rRNA sequence similarities ranged from 90 to $100 \%$. The species of group 2 were saccharolytic organisms and the diamino acid in their peptidoglycan was lysine. Their rRNA sequence similarities ranged from $87 \cdot 42$ to $100 \%$. Group 3 organisms were butyrate-negative and 


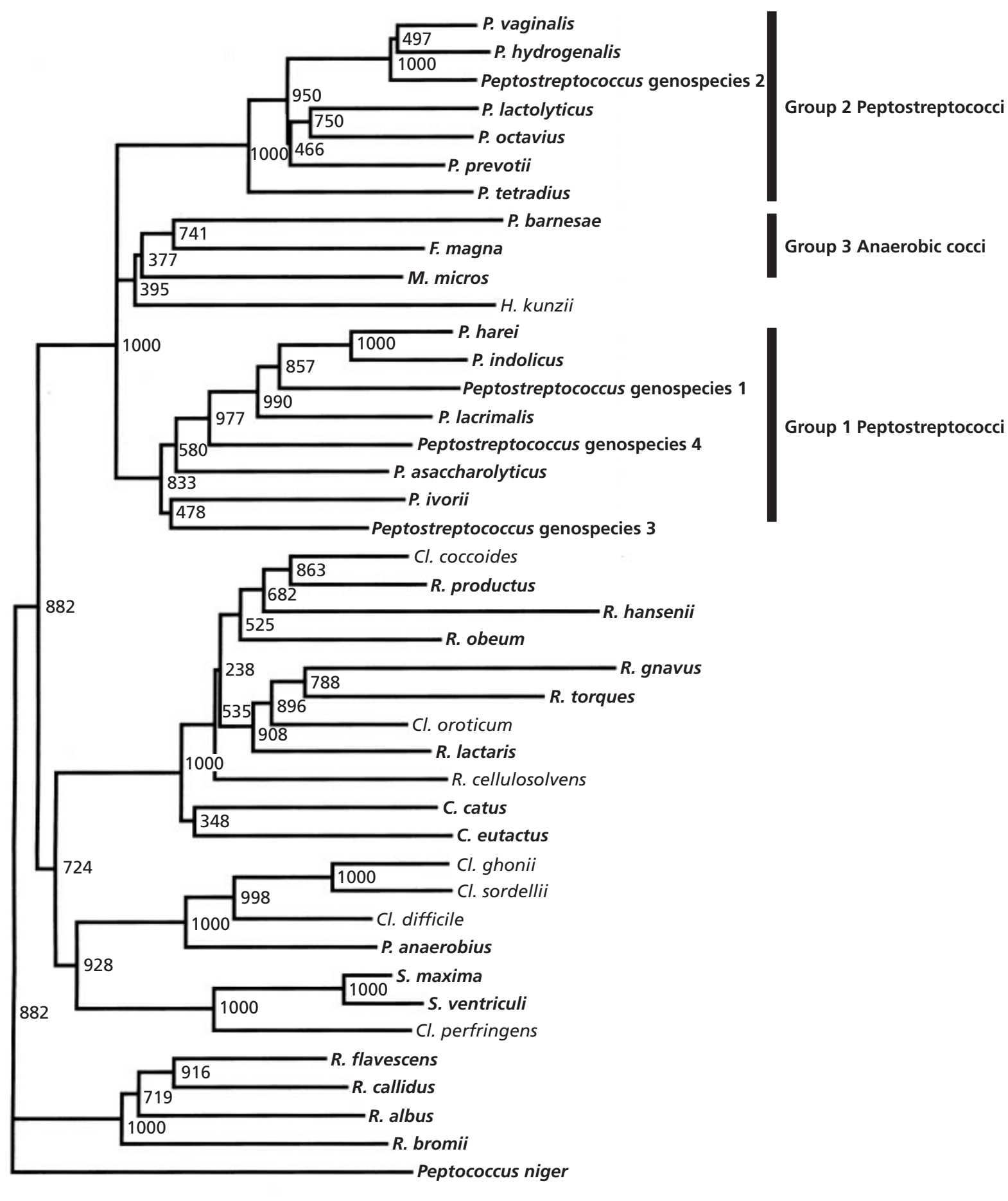

$0 \cdot 1$

Fig. 1. Phylogenetic tree of anaerobic cocci based on $16 \mathrm{~S}$ rDNA sequences. Bold type indicates obligately anaerobic cocci. Genera are abbreviated as: P., Peptostreptococcus; F., Finegoldia; M., Micromonas; H., Helcococcus; Cl., Clostridium; S., Sarcina; C., Coprococcus; R., Ruminococcus; E., Eubacterium.

their peptidoglycan structures were variable. Their rRNA sequence similarities ranged from 87.67 to $100 \%$. Two species of group 3 were recently reclassified in new monospecific genera as Finegoldia magna and Micromonas micros (Murdoch \& Shah, 1999, 2000), although the genus name Micromonas is illegitimate under Rule 51b(4) of the Bacteriological Code because it is already the name of a genus of fungi 
Table 2. Characteristics that differentiate members of the three new genera from other strictly anaerobic, Gram-positive cocci

Taxa are identified as: 1, Anaerococcus prevotii (type species); 2, Anaerococcus tetradius; 3, Anaerococcus lactolyticus; 4, Anaerococcus hydrogenalis; 5, Anaerococcus octavius; 6, Anaerococcus vaginalis; 7, Peptoniphilus asaccharolyticus (type species); 8 , Peptoniphilus lacrimalis; 9, Peptoniphilus harei; 10, Peptoniphilus ivorii; 11, Peptoniphilus indolicus; 12, Gallicola barnesae (type species); 13, Finegoldia magna (type species); 14, Micromonas micros (type species); 15, Peptostreptococcus anaerobius (type species); 16, Peptococcus niger (type species); 17, Ruminococcus flavefaciens (type species); 18, Coprococcus eutactus (type species); 19, Sarcina ventriculi (type species); 20, Sarcina maxima. All taxa stain Gram-positive. Abbreviations: Dap, diaminopimelic acid; Orn, ornithine.

\begin{tabular}{|c|c|c|c|c|c|c|c|c|c|c|c|c|c|c|c|c|c|c|c|c|}
\hline Characteristic & 1 & 2 & 3 & 4 & 5 & 6 & 7 & 8 & 9 & 10 & 11 & 12 & 13 & 14 & 15 & 16 & 17 & 18 & 19 & 20 \\
\hline $\begin{array}{l}\text { DNA G }+ \text { C content } \\
(\mathrm{mol} \%)^{*}\end{array}$ & $29-33$ & $30-32$ & $30-34$ & $30-34$ & $26-31$ & $30-34$ & $31-32$ & $30-34$ & 25 & 29 & $32-35$ & $32-34$ & $32-34$ & $28-30$ & $34-36$ & $50-51$ & $39-45$ & $39-42$ & $28-31$ & $28-31$ \\
\hline Peptidoglycan $\dagger$ & $\begin{array}{l}\text { Lys, } \\
\text { D-Glu }\end{array}$ & $\begin{array}{l}\text { Lys, } \\
\text { D-Glu }\end{array}$ & $\begin{array}{l}\text { Lys, } \\
\text { D-Glu }\end{array}$ & $\begin{array}{l}\text { Lys, } \\
\text { D-Glu }\end{array}$ & $\begin{array}{l}\text { Lys, } \\
\text { D-Asp }\end{array}$ & $\begin{array}{l}\text { Lys, } \\
\text { D-Glu }\end{array}$ & $\begin{array}{l}\text { Orn, } \\
\text { D-Glu }\end{array}$ & $\begin{array}{l}\text { Orn, } \\
\text { D-Glu }\end{array}$ & $\begin{array}{l}\text { Orn, } \\
\text { D-Glu }\end{array}$ & $\begin{array}{l}\text { Orn, } \\
\text { D-Glu }\end{array}$ & $\begin{array}{l}\text { Orn, } \\
\text { D-Glu }\end{array}$ & $\begin{array}{l}\text { Orn, } \\
\text { D-Asp }\end{array}$ & $\begin{array}{l}\text { Lys, } \\
\text { Gly }\end{array}$ & $\begin{array}{l}\text { Lys, } \\
\text { D-Asp }\end{array}$ & $\begin{array}{l}\text { Lys, } \\
\text { D-Asp }\end{array}$ & $\begin{array}{l}\text { Lys, } \\
\text { D-Asp }\end{array}$ & $\begin{array}{c}\text { mDap, } \\
\text { none }\end{array}$ & $\begin{array}{c}\text { mDap, } \\
\text { none }\end{array}$ & $\begin{array}{l}\text { LLDap, } \\
\text { Gly }\end{array}$ & $\begin{array}{l}\text { LLDap } \\
\text { Gly }\end{array}$ \\
\hline \multicolumn{21}{|c|}{ - } \\
\hline Butyrate & + & + & + & + & + & + & + & + & + & + & + & - & - & - & + & + & - & + & - & + \\
\hline Caproate & - & - & - & - & + & - & - & - & - & - & - & - & - & - & + & + & - & - & - & - \\
\hline $\begin{array}{l}\text { Peptone as major } \\
\text { energy source }\end{array}$ & + & + & + & + & + & + & + & + & + & + & + & + & + & + & + & + & - & - & - & - \\
\hline Sugar fermented & + & + & + & + & + & + & - & - & - & - & - & - & - & - & + & - & + & + & + & + \\
\hline $\begin{array}{l}\text { Sugar required for } \\
\text { growth }\end{array}$ & - & - & - & - & - & - & - & - & - & - & - & - & - & - & - & - & + & + & + & + \\
\hline
\end{tabular}

* Values in columns 16-20 are ranges for the particular genera.

$\dagger$ Position 3 (diamino acid) and the interpeptide bridge are listed.

(see http://www.bacterio.cict.fr/m/micromonas.html). Peptostreptococcus barnesae remained in the genus Peptostreptococcus.

The obligately anaerobic, Gram-positive cocci were once classified in the family Peptococcaceae Kluyver and van Niel 1936 (Rogosa, 1974). This family included the genera Ruminococcus, Coprococcus, Sarcina, Peptococcus and Peptostreptococcus. Most members of these genera were found in the phylum Firmicutes. Sarcina ventriculi has $95 \%$ sequence similarity to Clostridium perfringens and is related to clostridial group I (Li et al., 1994; Collins et al., 1994). Peptostreptococcus anaerobius was related to Clostridium sordellii of clostridial group XI (Collins et al., 1994). The ruminococci were separated into two major different phyla (Rainey \& Janssen, 1995) and the coprococci were also related to clostridial group XVI. Thus, all of the type species of the members of the family Peptococcaceae were reclassified into different clostridial groups. This means that the family Peptococcaceae is no longer a legitimate classification.

The members of the genus Peptostreptococcus were also scattered into different clostridial groups. Peptostreptococcus anaerobius, the type species of the genus, was related to group XI of the clostridia. This group also contains Clostridium difficile and Clostridium sordellii. The other peptostreptococci were clustered into three different groups. No published clostridial species were clustered within each of these groups. As indicated in Table 2, the cell wall structures of these organisms support this grouping, with the exception of group 3.
Members of group 1 use peptone as a major energy source and produce butyrate as their metabolic endproduct. They are non-saccharolytic organisms. We propose a new genus, Peptoniphilus gen. nov., to contain Peptostreptococcus asaccharolyticus, Peptostreptococcus indolicus, Peptostreptococcus lacrimalis, Peptostreptococcus harei and Peptostreptococcus ivorii.

The group 2 organisms are saccharolytic and produce butyrate as a major metabolic end-product. We propose a new genus, Anaerococcus gen. nov., for the group 2 organisms Peptostreptococcus prevotii, Peptostreptococcus hydrogenalis, Peptostreptococcus vaginalis, Peptostreptococcus lactolyticus, Peptostreptococcus tetradius and Peptostreptococcus octavius.

Group 3 contained Peptostreptococcus barnesae and two newly reclassified species (Murdoch \& Shah, 1999). Finegoldia magna and Micromonas micros were previously members of the genus Peptostreptococcus; they were validly reclassified in new monospecific genera (Murdoch \& Shah, 2000), but Peptostreptococcus barnesae was left in the genus Peptostreptococcus. We propose to reclassify Peptostreptococcus barnesae as the type species of a new genus, Gallicola gen. nov., as Gallicola barnesae comb. nov.

\section{Description of Peptoniphilus gen. nov.}

Peptoniphilus (Pep.to.ni.phil'us. N.L. neut. n. peptonum peptone; Gr. adj. philos liking, friendly to; N.L. masc. n. Peptoniphilus friend of peptone, referring to the use of peptone as a major energy source). 
Table 3. Biochemical differentiation of reclassified Peptostreptococcus species

Taxa are identified as: 1, Anaerococcus prevotii (type species); 2, Anaerococcus tetradius; 3, Anaerococcus lactolyticus; 4 , Anaerococcus hydrogenalis; 5, Anaerococcus octavius; 6, Anaerococcus vaginalis; 7, Peptoniphilus asaccharolyticus (type species); 8 , Peptoniphilus lacrimalis; 9, Peptoniphilus harei; 10, Peptoniphilus ivorii; 11, Peptoniphilus indolicus; 12, Gallicola barnesae (type species); 13, Finegoldia magna (type species); 14, Micromonas micros (type species); 15, Peptostreptococcus anaerobius (type species); 16, Peptococcus niger (type species). Characteristics are scored as: +, positive; -, negative; D, strain-dependent; w, weak.

\begin{tabular}{|c|c|c|c|c|c|c|c|c|c|c|c|c|c|c|c|c|}
\hline Characteristic & 1 & 2 & 3 & 4 & 5 & 6 & 7 & 8 & 9 & 10 & 11 & 12 & 13 & 14 & 15 & 16 \\
\hline Major terminal volatile fatty acid* & B & B & B & B & $\mathrm{B}, \mathrm{C}$ & B & B & B & B & B & B & $\mathrm{A}, \mathrm{B}$ & A & A & IC, IV & $\mathrm{C}$ \\
\hline \multicolumn{17}{|l|}{ Production of: } \\
\hline Indole & - & - & - & + & - & $\mathrm{D}$ & $\mathrm{D}$ & - & $\mathrm{D}$ & - & + & w & - & - & - & - \\
\hline Urease & $\mathrm{D}$ & + & + & $\mathrm{D}$ & - & - & - & - & - & - & - & - & - & - & - & - \\
\hline Alkaline phosphatase & - & - & - & $\mathrm{D}$ & - & $\mathrm{D}$ & - & - & - & - & + & - & $\mathrm{D}$ & + & - & - \\
\hline Coagulase & - & - & - & - & - & - & - & - & - & - & + & - & - & - & - & - \\
\hline \multicolumn{17}{|l|}{ Fermentation of: } \\
\hline Glucose & $\mathrm{D}$ & $\mathrm{D}$ & + & + & + & + & - & - & - & - & - & - & - & - & + & - \\
\hline Lactose & - & - & + & + & - & - & - & - & - & - & - & - & - & - & - & - \\
\hline Raffinose & + & - & - & + & - & - & - & - & - & - & - & - & - & - & - & - \\
\hline Mannose & + & + & + & + & + & $\mathrm{D}$ & - & - & - & - & - & - & - & - & + & - \\
\hline \multicolumn{17}{|l|}{ Activity of: } \\
\hline$\alpha$-Galactosidase & + & - & - & - & - & - & - & - & - & - & - & - & - & - & - & - \\
\hline$\beta$-Galactosidase & - & - & + & - & - & - & - & - & - & - & - & - & - & - & - & - \\
\hline$\alpha$-Glucosidase & + & + & - & $\mathrm{D}$ & - & - & - & - & - & - & - & - & - & - & $\mathrm{w}$ & - \\
\hline$\beta$-Glucosidase & + & + & - & - & - & - & - & - & - & - & - & - & - & - & - & - \\
\hline Arginine arylamidase & + & + & + & - & - & + & + & + & + & - & + & - & + & + & - & - \\
\hline Proline arylamidase & - & - & - & - & + & - & - & - & - & + & - & - & - & + & + & - \\
\hline Phenylalanine arylamidase & - & $\mathrm{W}$ & - & - & - & - & - & + & - & - & + & - & - & - & - & - \\
\hline Leucine arylamidase & - & + & - & - & - & + & $\mathrm{D}$ & + & $\mathrm{D}$ & - & + & - & + & + & - & - \\
\hline Pyroglutamyl arylamidase & + & $\mathrm{W}$ & - & - & $\mathrm{w}$ & - & - & - & - & - & - & - & + & + & - & - \\
\hline Histidine arylamidase & + & $\mathrm{w}$ & - & - & - & + & $\mathrm{w}$ & + & + & - & + & - & $\mathrm{D}$ & + & - & - \\
\hline
\end{tabular}

$*_{B}$, Butyrate; C, caproate; IC, isocaproate; IV, isovalerate; A, acetate.

Non-spore-forming, Gram-positive, obligately anaerobic cocci. Cells may occur in pairs, short chains, tetrads or small clusters. Non-motile. The major cellular fatty acid is C18:1 (Ezaki et al., 1983). Carbohydrates are not fermented. The major metabolic end-product from peptone/yeast extract/glucose (PYG) medium is butyric acid. The cell wall diamino acid is ornithine and the interpeptide bridge is Dglutamic acid. The $\mathrm{G}+\mathrm{C}$ content of DNA of members of this genus is $30-34 \mathrm{~mol} \%$ (Ezaki et al., 1983). Characteristics that differentiate this genus from other genera are given in Table 2. The type species is Peptoniphilus asaccharolyticus.

\section{Description of Peptoniphilus asaccharolyticus comb. nov.}

Basonym: Peptostreptococcus asaccharolyticus (Distaso 1912) Ezaki et al. 1983.

Often isolated from various human clinical specimens such as vaginal discharges and ovarian and peritoneal abscesses. Most strains produce indole. Negative for urease, alkaline phosphatase, arginine dihydrolase and coagulase. Does not produce acid from carbohydrates. Major metabolic end-product from PYG is butyric acid. Descriptions of major saccharolytic and proteolytic enzymes are given by Murdoch (1998). Characteristics that differentiate this species from other members of the genus are given in Tables 2 and 3. The DNA G + C content is $31-32 \mathrm{~mol} \%$. The type strain is ATCC $14963^{\mathrm{T}}$.

\section{Description of Peptoniphilus indolicus comb. nov.}

Basonym: Peptostreptococcus indolicus (Christiansen 1934) Ezaki et al. 1983.

Isolated from summer mastitis of cattle. Most strains are coagulase-, alkaline phosphatase- and indolepositive. Negative for urease and arginine dihydrolase. No sugars are fermented. Major metabolic endproduct from PYG is butyric acid. Descriptions of major saccharolytic and proteolytic enzymes are given by Murdoch (1998). Biochemical traits that differentiate this species from other species are given in Tables 2 and 3. The DNA $\mathrm{G}+\mathrm{C}$ content is $32-34 \mathrm{~mol} \%$. The type strain is ATCC $29427^{\mathrm{T}}$. 


\section{Description of Peptoniphilus lacrimalis comb. nov.}

Basonym: Peptostreptococcus lacrimalis Li et al. 1992.

Isolated from a human lachrymal gland abscess. Negative for indole, urease, arginine dihydrolase, alkaline phosphatase and coagulase. Carbohydrates are not fermented. Major metabolic end-product from PYG is butyric acid. Production of major saccharolytic and proteolytic enzymes is described by Murdoch (1998). A full description is given by Li et al. (1992). Differential characteristics are given in Tables 2 and 3. The DNA G $+\mathrm{C}$ content is $30-34 \mathrm{~mol} \%$. The type strain is GIFU $7667^{\mathrm{T}}\left(=\mathrm{JCM} 8139^{\mathrm{T}}\right)$.

\section{Description of Peptoniphilus harei comb. nov.}

Basonym: Peptostreptococcus harei Murdoch et al. 1997.

The type strain was isolated from pus of a human sacral ulcer. Some strains produce indole. Negative for urease, arginine dihydrolase, alkaline phosphatase and coagulase. Carbohydrates are not fermented. Major metabolic end-product from PYG is butyric acid. Production of major saccharolytic and proteolytic enzymes is described by Murdoch (1998). Differential characteristics are given in Tables 2 and 3. The DNA $\mathrm{G}+\mathrm{C}$ content is $25 \mathrm{~mol} \%$. The type strain is DSM $10020^{\mathrm{T}}$

\section{Description of Peptoniphilus ivorii comb. nov.}

Basonym: Peptostreptococcus ivorii Murdoch et al. 1997.

The type strain was isolated from a human leg ulcer. Negative for urease, arginine dihydrolase, alkaline phosphatase and coagulase. Carbohydrates are not fermented. Major metabolic end-product from PYG is butyric acid. Production of major saccharolytic and proteolytic enzymes is described by Murdoch (1998). Differential characteristics are given in Tables 2 and 3. The DNA G $+\mathrm{C}$ content is $29 \mathrm{~mol} \%$. The type strain is DSM $10022^{\mathrm{T}}$.

\section{Description of Anaerococcus gen. nov.}

Anaerococcus (An.ae.ro.coc'cus. Gr. prep. an without; Gr. n. aer air; L. masc. n. coccus berry, coccus; N.L. masc. n. Anaerococcus anaerobic coccus).

Strictly anaerobic, Gram-positive, non-motile cocci. Cells are found in pairs, tetrads, irregular masses or chains. Metabolize peptones and amino acids and the major metabolic end-products from PYG medium are butyric acid, lactic acid and small amounts of propionic and succinic acids. Most species are able to ferment several carbohydrates, but most are weakly fermentative. Glucose, fructose, sucrose and lactose are major fermentative sugars. Most species do not produce indole. The diamino acid of the cell wall is $\mathrm{L}$ lysine. The interpeptide bridge is D-glutamic acid, except in the case of Aerococcus octavius. Descriptions of major saccharolytic and proteolytic enzymes are given by Murdoch (1998). Characteristics that differentiate members from other genera are given in Table 2. Members of the genus are typically isolated from the human vagina and various purulent secretions. The $\mathrm{G}+\mathrm{C}$ content of the DNA is 25-33 $\mathrm{mol} \%\left(T_{\mathrm{m}}\right)$. The type species is Anaerococcus prevotii.

\section{Description of Anaerococcus prevotii comb. nov.}

Basonym: Peptostreptococcus prevotii (Foubert and Douglas 1948) Ezaki et al. 1983.

Often isolated from human clinical specimens such as vaginal discharges and ovarian, peritoneal and sacral abscesses. Negative for indole, alkaline phosphatase and coagulase. Some strains produce urease. Most strains ferment glucose and mannose. Acid is also produced from raffinose, ribose and mannose. No acid produced from lactose, cellobiose, maltose, sucrose or xylose. Major metabolic end-product from PYG is butyric acid. Descriptions of major saccharolytic and proteolytic enzymes are given by Murdoch (1998). Differential characteristics from other members of the genus are given in Table 3 . The $\mathrm{G}+\mathrm{C}$ content of the DNA is $29-33 \mathrm{~mol} \%$. The type strain is ATCC $9321^{\mathrm{T}}$.

\section{Description of Anaerococcus tetradius comb. nov.}

Basonym: Peptostreptococcus tetradius (ex Choukévitch 1911) Ezaki et al. 1983.

Isolated from vaginal discharges and ovarian abscesses. Urease-positive. Negative for indole, alkaline phosphatase, arginine dihydrolase and coagulase. Glucose and mannose are fermented. Acid is not produced from lactose, raffinose, ribose, cellulose, maltose, sucrose or xylose. Major metabolic endproduct from PYG is butyric acid. Descriptions of major saccharolytic and proteolytic enzymes are given by Murdoch (1998). Differential characteristics from other members of the genus are given in Table 3 . The DNA G + C content is $30-32 \mathrm{~mol} \%$. The type strain is GIFU $7672^{\mathrm{T}}\left(=\mathrm{JCM} 1964^{\mathrm{T}}\right)$.

\section{Description of Anaerococcus hydrogenalis comb. nov.}

Basonym: Peptostreptococcus hydrogenalis Ezaki et al. 1990.

Organism is isolated from vaginal discharges and ovarian abscesses. Produces abundant hydrogen gas from PYG. Indole-positive. Some strains produce urease and alkaline phosphatase. Acid is produced from glucose, lactose, raffinose and mannose. Negative for arginine dihydrolase and coagulase. Major metabolic end-product from PYG is butyric acid. A full description is given by Ezaki et al. (1990). Descriptions of major saccharolytic and proteolytic enzymes are given by Murdoch (1998). Differential characteristics from other members of the genus are given in Table 3. The DNA $\mathrm{G}+\mathrm{C}$ content is $30-34 \mathrm{~mol} \%$. The type strain is GIFU $7662^{\mathrm{T}}\left(=\mathrm{JCM} 7635^{\mathrm{T}}\right)$. 
Description of Anaerococcus vaginalis comb. nov.

Basonym: Peptostreptococcus vaginalis Li et al. 1992.

Isolated from vaginal discharges and ovarian abscesses. Produces arginine dihydrolase. Some strains are positive for indole and alkaline phosphatase. Coagulase and urease are negative. Major metabolic end-product from PYG is butyric acid. Descriptions of major saccharolytic and proteolytic enzymes are given by Murdoch (1998). Differential characteristics from other members of the genus are given in Table 3. A full description is given by Li et al. (1992). The DNA G + C content is $30-34 \mathrm{~mol} \%$. The type strain is GIFU $12669^{\mathrm{T}}\left(=\mathrm{JCM} 8138^{\mathrm{T}}\right)$.

\section{Description of Anaerococcus lactolyticus comb. nov.}

Basonym: Peptostreptococcus lactolyticus $\mathrm{Li}$ et al. 1992.

Isolated from vaginal discharges and ovarian abscesses. Urease-positive. Negative for indole, alkaline phosphatase, arginine dihydrolase and coagulase. Acid from glucose, lactose and mannose. Raffinose and ribose are not fermented. Major metabolic end-product from PYG is butyric acid. A full description is given by Li et al. (1992). Descriptions of major saccharolytic and proteolytic enzymes are given by Murdoch (1998). Differential characteristics from other members of the genus are given in Table 3 . The DNA G + C content is $30-34 \mathrm{~mol} \%$. The type strain is GIFU 8586 ${ }^{\mathrm{T}}\left(=\mathrm{JCM} 8140^{\mathrm{T}}\right)$.

\section{Description of Anaerococcus octavius comb. nov.}

Basonym: Peptostreptococcus octavius Murdoch et al. 1997.

The type strain was isolated from a human nasal cavity. Often isolated from skin, vagina and nasal cavity. Indole, urease, alkaline phosphatase, arginine dihydrolase and coagulase are negative. Glucose, ribose and mannose are fermented. Lactose and raffinose are not fermented. Major metabolic endproducts from PYG are butyric acid and caproic acid. A full description is given by Murdoch et al. (1997). The cell wall diamino acid is lysine and the interpeptide bridge contains D-aspartic acid; this peptidoglycan structure is different from other members of the genus Anaerococcus. Descriptions of major saccharolytic and proteolytic enzymes are given by Murdoch (1998). Differential characteristics from other members of the genus are given in Table 3 . The DNA G $+\mathrm{C}$ content is 26-31 mol\%. The type strain is NCTC $9810^{\mathrm{T}}$.

\section{Description of Gallicola gen. nov.}

Gallicola (Gal.li'co.la. L. n. gallus rooster/chicken; L. masc. suffix -cola inhabitant.; N.L. masc. n. Gallicola inhabitant of chickens, referring to the isolation of the type species from chicken faeces).
Obligately anaerobic, Gram-positive, non-motile cocci that occur singly and in pairs. Carbohydrates are not fermented. Indole is negative. Peptidoglycan diamino acid is ornithine and the interpeptide bridge is Daspartic acid. The metabolic end-products from PYG medium are acetic and lactic acids. The $\mathrm{G}+\mathrm{C}$ content of the DNA is $27-34 \mathrm{~mol} \%\left(T_{\mathrm{m}}\right)$ (Ezaki et al., 1983; Schiefer-Ullrich \& Andreesen, 1985). The type and only species is Gallicola barnesae.

\section{Description of Gallicola barnesae comb. nov.}

Basonym: Peptostreptococcus barnesae SchieferUllrich and Andreesen 1986.

Isolated from chicken faeces. Negative for the production of indole, urease, alkaline phosphatase, arginine dihydrolase and coagulase. A full description is given by Schiefer-Ullrich \& Andreesen (1985). Glucose, lactose, raffinose, ribose and mannose are not fermented. The metabolic end-products from PYG medium are acetic and butyric acids. Descriptions of major saccharolytic and proteolytic enzymes are given by Murdoch (1998). Differential characteristics from other members of the genus are given in Table 3 . The $\mathrm{G}+\mathrm{C}$ content of the DNA is $32-34 \mathrm{~mol} \%$. The type strain is DSM $3244^{\mathrm{T}}$.

\section{Emended description of Peptostreptococcus Kluyver and van Niel 1936}

Obligately anaerobic, Gram-positive, non-motile cocci and coccobacilli. Cells are usually arranged in chains. Cell wall diamino acid is L-lysine and the interpeptide bridge is D-aspartate. The $\mathrm{G}+\mathrm{C}$ content of the DNA is 33-34 mol \% $\left(T_{\mathrm{m}}\right)$. Weakly saccharolytic. Negative for indole, urease, alkaline phosphatase, arginine dihydrolase and coagulase. Most strains produce acid from glucose. Some strains produce acid from mannose, maltose or sucrose. The metabolic end-products from PYG medium are acetic, butyric, isobutyric, isovaleric and isocaproic acids. Nitrate is not reduced to nitrite. Aesculin is not hydrolysed. The type species is Peptostreptococcus anaerobius, the only remaining member of the genus. Peptostreptococcus anaerobius is classified phylogenetically in clostridial group XI. The type strain of Peptostreptococcus anaerobius is NCTC $11460^{\mathrm{T}}$.

\section{ACKNOWLEDGEMENTS}

We are grateful to Professor Hans G. Trüper for giving us kind suggestions on the Latin nomenclature of the new genera. This work was partially supported by the Yakult Research Fund on Intestinal Flora.

\section{REFERENCES}

Collins, M. D., Lawson, P. A., Willems, A., Cordoba, J. J., Fernandez-Garayzabal, J., Garcia, P., Cai, J., Hippe, H. \& Farrow, J. A. E. (1994). The phylogeny of the genus Clostridium: proposal 
of five new genera and eleven new species combinations. Int $J$ Syst Bacteriol 44, 812-826.

Ezaki, T., Yamamoto, H., Ninomiya, K., Suzuki, S. \& Yabuuchi, E. (1983). Transfer of Peptococcus indolicus, Peptococcus asaccharolyticus, Peptococcus prevotii, and Peptococcus magnus to the genus Peptostreptococcus and proposal of Peptostreptococcus tetradius sp. nov. Int J Syst Bacteriol 33, 683-698.

Ezaki, T., Liu, S.-L., Hashimoto, H. \& Yabuuchi, E. (1990). Peptostreptococcus hydrogenalis sp. nov. from human fecal and vaginal flora. Int J Syst Bacteriol 40, 305-306.

Li, N., Hashimoto, Y., Adnan, S., Miura, H., Yamamoto, H. \& Ezaki, T. (1992). Three new species of the genus Peptostreptococcus isolated from humans: Peptostreptococcus vaginalis sp. nov., Peptostreptococcus lacrimalis sp. nov., and Peptostreptococcus lactolyticus sp. nov. Int J Syst Bacteriol 42, 602-605.

Li, N., Hashimoto, Y. \& Ezaki, T. (1994). Determination of $16 \mathrm{~S}$ ribosomal RNA sequences of all members of the genus Peptostreptococcus and their phylogenetic position. FEMS Microbiol Lett 116, 1-5.

Murdoch, D. A. (1998). Gram-positive anaerobic cocci. Clin Microbiol Rev 11, 81-120.

Murdoch, D. A. \& Shah, H. N. (1999). Reclassification of Peptostreptococcus magnus (Prevot 1933) Holdeman and Moore 1972 as Finegoldia magna comb. nov. and Peptostreptococcus micros (Prevot 1933) Smith 1957 as Micromonas micros comb. nov. Anaerobe 5, 555-559.

Murdoch, D. A. \& Shah, H. N. (2000). Micromonas micros comb. nov. (basonym Peptostreptococcus micros) and Finegoldia magna comb. nov. (basonym Peptostreptococcus magnus). In Validation of the Publication of New Names and New Combinations Previously Effectively Published Outside the IJSEM, List no. 75. Int J Syst Evol Microbiol 50, 1415-1417.

Murdoch, D. A., Collins, M. D., Willems, A., Hardie, J. M., Young, K. A. \& Magee, J. T. (1997). Description of three new species of the genus Peptostreptococcus from human clinical specimens: Peptostreptococcus harei sp. nov., Peptostreptococcus ivorii sp. nov., and Peptostreptococcus octavius sp. nov. Int J Syst Bacteriol 47, 781-787.

Rainey, F. A. \& Janssen, P. H. (1995). Phylogenetic analysis by $16 \mathrm{~S}$ ribosomal DNA sequence comparison reveals two unrelated groups of species within the genus Ruminococcus. FEMS Microbiol Lett 129, 69-73.

Rogosa, M. (1974). Family III. Peptococcaceae Rogosa 1971. In Bergey's Manual of Determinative Bacteriology, 8th edn, pp. 517-528. Edited by R. E. Buchanan \& N. E. Gibbons. Baltimore: Williams \& Wilkins.

Saitou, N. \& Nei, M. (1986). The neighbor-joining method: a new method for reconstructing phylogenetic trees. Mol Biol Evol 4, 406-425.

Schiefer-Ullrich, H. \& Andreesen, J. R. (1985). Peptostreptococcus barnesae sp. nov., a Gram-positive, anaerobic, obligately purine utilizing coccus from chicken feces. Arch Microbiol 143, 26-31.

Thompson, J. D., Higgins, D. G. \& Gibson, T. J. (1994). CLUSTAL $\mathrm{W}$ : improving the sensitivity of progressive multiple sequence alignment through sequence weighting, position-specific gap penalties and weight matrix choice. Nucleic Acids Res 22, 4673-4680. 